\title{
An Impact Assessment of Flooding on Food Security among Rural Farmers in Dagiri Community, of Gwagwalada Area Council, Abuja, Nigeria
}

\author{
Ikani Daniel Idoko
}

Centre for Risk Disaster Management and Development Studies, Federal University of Technology, Minna, Niger State, Nigeria

\begin{abstract}
This research Paper assessed the impact of flood on food security of rural farmers in Dagiri Community of Gagwalada Area Council of Abuja Nigeria. The sampling frame for the study consist of rural farmers in Dagiri community and sampling technique used was random sampling of 112 farmers household living along the River Usuma because they are most prone to flooding. Data were analysed using simple descriptive statistics and confidence interval using 95\% confidence level. The results showed that, in dagiri Community areas lying along the banks of River Usman where lots of farming activities takes place are most vulnerable to flood disaster. The continuous violation of land use planning, population explosion, and poor quality materials used in construction of buildings increases the towns' vulnerability to flood hazard. The damages caused rural farmers in Dagiri Community by the flood is colossal, it includes destruction of farm houses, stored farm produce and household properties. Flood waters also wash away crops and farm land, leading to food insecurity. In reducing the vulnerability of Dagiri community to flood to make the community resilient and food secured there is need for the council to institute improved land use planning, removal of structures from river Usman flood plains and discourage farmers from farming and living close to the river. More measures include intensifying environmental education of residents especially in the areas of flood risk and coopt the active participation of government agencies and the Community in a Community based flood risk management.
\end{abstract}

Keywords: Flood risk hazards, Community resilience, Flood Management, Food security, Vulnerability, Agricultural productivity.

\section{Introduction}

\subsection{Background to the Study}

Floods cause large scale destruction leading to massive socioeconomic and environmental damages to human lives, structures, properties and the farm lands, thereby inflicting extreme suffering on the communities affected. Disasters hamper sustainable development food security and growth. The losses from natural disasters like flood are increasing and have a disproportionate impact on less developed countries. They devastate the standard of living and overall development prospects.

Recognizing the importance of disaster mitigation and management, in order to avoid the enormous losses from flood disasters leading to food insecurity, the world Bank's assistance is moving away from traditional relief and reconstruction towards supporting the culture of prevention for sustainable development. This new approach increasingly relies on knowledge sharing, creating communities of practice, and raising awareness in disaster risk management targeting government officials, civil society, and local communities prone to flood.

There is also enough evidence to show, that the rise in flood disasters and consequently food insecurity is related to the rise in the vulnerability of people all over the world. This rise in flood disaster was induced by the human determined path of development. Noteworthy also was the recognition that this increase in vulnerability was not uniform. There were large variations across regions, nations, provinces, cities, communities, socioeconomic classes, castes, and even gender, with poverty and illiteracy being the leading cause of vulnerability especially in sub sharan Africa .

The world Bank in one of its publication defined food security as being able at all times to have access to food in the quantity and quality desired for an active, healthy life World Bank [1]. Food and Agriculture Organization $\mathrm{FAO}$ [2] in its definition of food security emphasized that, food security must encompass access to preferred food. It is instructive to note that a household is said to be food secure if they are able to get and consume in a continuous manner nutritionally rich, healthy and preferred food through legally acceptable means to guarantee good health. When a household or a community lacks, or is potentially vulnerable due to the absence of one or more factors outlined in these definitions, the household or community is said to be food insecure [3].

The frequency of flooding in Nigeria is on the increase in Sept 2010 heavy rain started in the north and neighboring Niger republic, these led to serious flooding in three states, Sokoto, kebbi and Jigawa all in north east 
Nigeria causing human and material damages in the affected communities. The heavy downpour led to the overflow of the Hadejiariver, the situation further compounded by the release of water from Dams and poor drainage system. 1.5 million People were displaced with many casualty and farm land, crops and property worth millions of Naira destroyed [4].

In the year 2011 the heavy down pour of rain in Lagos which started on $10^{\text {th }}$ July and lasted for 17 hours led to massive flooding of Lagos metropolis the economic capital of Nigeria by the next day media report has it that 20 persons had lost their lives leading to 1500 families being displaced and needing immediate help from humanitarian agency [5]. From the realization that people's vulnerability is a key factor determining the impact of disasters on them, emphasis shifted to using "vulnerability analysis" as a tool in disaster management.

In recent years, a more comprehensive approach, that of disaster risk management, has emerged. This approach has three distinct but interrelated components: hazard assessment, vulnerability analysis, and enhancement of management capacity, and is more closely integrated with the ongoing development processes. Disasters are no longer viewed as extreme events created entirely by natural forces but the interaction of hazard and vulnerability with low coping capacity gives rise to disaster. The researcher therefore seeks to assess the impact of flood on food security of the rural farmers in Dagiri community of Gwagwalada,

\section{Review of Research Literature}

Many literatures suggests that households particularly those in developing countries, are vulnerable or food insecure due to limited economic and physical capacities as well as environmental disaster caused by flood. Because farmers households are vulnerable to flood, a presently food secure household is not guaranteed the same status in the coming season because of the unpredictable nature of flooding event. Jeronim, et al. [6] opined that the notion of food security is a dynamic rather than a static phenomenon depending on prevailing economical, physical and climatic circumstances.

Household food insecurity has been classified as either persistent or transitory. Persistent food insecurity signifies continuous food crisis caused by the continual inability of households to acquire needed food, either through market purchases by money or through own production as farmers [7]. On the other hand, transitory food insecurity is a temporary decline in a household's access to needed food due to instability in food prices, production or income. It signifies a short time inadequacy in households' to meet food requirement, which obligates the vulnerable households to devise coping mechanism in order to bridge their food consumption gap. Whether persistent or transitory, food insecurity remains a great problem to developing countries particularly, in subSaharan Africa which account for a significant share in the World's population. The Population Reference Bureau [8] states that the World's population is approximately 7.137 billion, out of which 1.030 billion (15\%) are in Africa. Food and agriculture report [9] showed that out of about 925 million people worldwide still suffering from food insecurity, 235 million of them representing (25\%) are from sub-Sahara Africa. This trend as revealed by the Global Hunger Index (GHI) report of 2013 [10] indicated that hunger level in Africa is at crisis level with subSaharan Africa recording the second highest regional GHI after South Asia. Because of the global concern to curb this food crisis, world leaders have adopted a common strategy in the form of the Millennium Development Goal (MDG) which is targeted to reduce by half, the number of people who suffer from acute starvation and who earn less than $\$ 1$ per day by the year $2015[11]$.

The federal government of Nigeria has achieved positive result in the reduction of hunger as indicated by the drop in the country's GHI from 16.3 in 2005 to 15 in 2013 [10]. This achievement is however, still far above the safe and comfortable globally accepted level of below 5 indicating that food insecurity is still a great problem in the Nigeria. Abimbola and Kayode [12] in their research findings noted a large proportion of Nigeria households are still food insecure despite the several efforts by successive governments to achieve food security through setting up of various agricultural development institutions, programmes and projects. Low household agricultural productivity and associated low income have resulted in persistent food insecurity particularly in the peasant farming household in rural areas. From the foregoing, it is evident that Nigeria households are far from being food secure and one of the major cause is the perennial flooding, the worst in the history of Nigeria occurring in $2012[13]$.

\subsection{General Concept of Hazards and Disasters}

A natural disaster is the effect of a natural hazard (e.g., flood, tornado, hurricane, volcanic eruption, earthquake, or landslide). It leads to financial, environmental or human losses. The resulting loss depends on the vulnerability of the affected population to resist the hazard, also called their resilience, this understanding is concentrated in the formulation: "disasters occur when hazards meet vulnerability."Wisner, et al. [14]. A natural hazard will hence never result in a natural disaster in areas without vulnerability, e.g. strong earthquakes in uninhabited areas, Luis Flores Ballesteros [15]. The term natural has consequently been disputed because the events simply are not hazards or disasters without human involvement, Alexander [16].

In identifying hazards in any Community in the view of Lavalla, et al. [17] requires hazard analysis which is defined as "a systematic investigation of potential disaster by analysing history, Vulnerability and probability". They also defined hazard identification as a structured approach for determining hazards that pose a significant threat to local Jurisdiction.

In the definition used by the United Nations, a disaster is considered to be "major" if the capability of the affected regions to cope with it is significantly exceeded and international aid is required. This is usually the case if the total number of individuals killed runs into thousands or the number made shelter less is measured in hundreds of thousands, or total damage in monetary terms or the insured damage is on an unusually large scale.

Obviously most natural disasters cannot be prevented, but plans to reduce the effects if such disasters strikes can be most effective. In addition steps can be taken which can in fact, eliminate or reduce the impact of disaster to the barest minimum. The need for man to cultivate the land, industrialization and urbanization has led to wanton and indiscriminate felling of trees, Gas flaring, and the use of fossil fuel which has led to environmental pollution, global warming and consequently increase in flooding incidents. 
Jayasselen [18] noted that to acquire data on the area or environments that are prone to hazards, an integrated approach of geospatial techniques, remote sensing and sound knowledge of geographical information systems are needed.

\subsection{The Concept of Flood}

Flooding is the over flowing of water either as a result of torrential rainfall, a broken Dam, a high rise in the volume of water in rivers, ocean or seas as a result of melting ice caps or prolong rainfall, there by flooding its neighbouring environment and beyond. Floods can be very dangerous depending on the nature and level of water volume involved.

Often when flowing water is termed "flood", danger or disaster is implied. Indeed floods have been associated with huge economic loses, disruption and loss of lives. Wisner, et al. [14] submits that floods accounted for the largest share of economic loses and fatalities from all natural hazards experience in the late 1980s and throughout the 1990 s.

According to Smith [19] 'more than any other environmental hazard, floods brings benefits as well as loses'. argues that they "are a natural phenomena that have always existed, and people have tried to use them to advantage to the extent possible."

Along the flooding river and downstream delta wetlands, such as those created by the Nile in Egypt and Niger in Nigeria floods are critical for maintaining and restoring many of the important services provided to humans by wetlands ecosystems. Flood associated benefits, according to Wisner, et al. [14] includes the provision of critical habitat for fish, waterfowl, and wildlife; maintenance of high levels of plants and animal diversity; replenishment of agricultural soil nutrients; and transporting sediments which maintain downstream deltas and coastal areas. These flooding areas have for long time attracted farming, fishing and hunting communities; and of late tourism ventures. Agricultural benefits from the more fertile soils with improved moisture retention; fishing opportunities are enhanced by nutrients rich waters brought to ponds, lakes, lagoons and river channels; While tourism is attracted by the scenic beauty of the unique water features as well as the rich variety of flora and fauna found in the area . There are different types of flood, examples are riverine flood, tsunami and coastal flood, tidal flood, man induced flood and flash flood.

\subsection{Agricultural Productivity}

According to Ojo [20] one major problem confronting small scale enterprise including that in agriculture is inadequate capital. Flood waters can make nonsense of whatever investment that has been made in agriculture. It is obvious that agriculture is the mainstay of the people of the sub-saharan Africa. It has been established that more than 70 percent of Nigerian population is engaged in agriculture [21] while 90 percent of Nigeria total food production comes from rural farmers and 60 percent of the country's population earn their leaving from these small farms owned by rural dwellers.

The federal government of Nigeria in its bid to increase agricultural productivity came up with several pogrammes among which are commercial agriculture credit scheme (CACS) in 2009 where the central bank of Nigeria (CBN) in collaboration with federal ministry of Agriculture and Water Resources (FMA \& WR) are to provide finance for the country's agricultural value chain (production, processing, storage and marketing). Increased production arising from the intervention is evident as seen in Nigeria having the highest Gross domestic product of 307 billion in Africa in the year 2014.

However the incidence of flooding in Dagiri Community of Gwagwalada Area Council occasioned by torrential rainfall or by overflow of river Usuma when the Dam is opened is a perennial problem faced by the inhabitants of Dagiri Community. The damages caused Dagiri community by floods is colossal, it includes destruction of crops, farm produce and farm land, business premises and houses, thereby leading to disruption of commercial activities, people are rendered homeless and in some cases family members separated, access roads are blocked and movement restricted. In worst cases they could be outbreak of Cholera and death Thecommunity faces untold hardship while battling with the impact of the flood. The flood has hampered sustainable development and also frustrated the millennial development goals of the Government especially in the area of food security.

\subsection{Flooding in Dagiri, Gwagwalada Area Council}

In Nigeria, Many lives and properties worth billions of Naira have been lost as a result of floods and its consequences every year. In most urban centers of the country most especially in fast growing towns like Gwagwalada town (FCT), and Dagiri the study area is undergoing rapid rate of urbanization, developmental processes are now taking places even outside where was earlier considered as the Gwagwalada boundary.

The vulnerability level of Dagiri community to flooding is very high this is because of the high population concentration, high degree of planning violation in the areas, old nature of houses and poor nature of materials used in building of the houses, indiscriminate solid waste disposal in canals, streams and River Usuma. High level of concentration of houses around the streams and River Usman draining the town causes serious constriction of the streams leading to an unease flow of surface water after a heavy down pour, which leads to flash flood. It was also discovered that clogging of drains which are usually caused by dumping of solid waste in the drainage system is very rampant and a usual thing in these area such careless behavior no doubt increases flood vulnerability of Dagiri Community.

\subsection{Map of Abuja showing Gwagwalada Area Council}

The Map of Abuja showing Gwagwalada Area Council (Figure 1.1) River Usman is also identified on the map. Gwagwalada is one of six Area Council of the Federal Capital Territory of Nigeria. The town is 50 minutes drive about $45 \mathrm{~km}$ away from the Federal Capital City (FCC); it is one of the six Area Council headquarters of the FCT. The town lies in the downstream of River Usuma and located between latitude $8^{\circ} 55^{\prime}$ and $9^{\circ} 00^{\prime} \mathrm{N}$ and longitudinal $7^{\circ} \mathrm{OO}^{\prime}$ and $7^{\circ} \mathrm{O} 5^{\prime} \mathrm{E}$. 


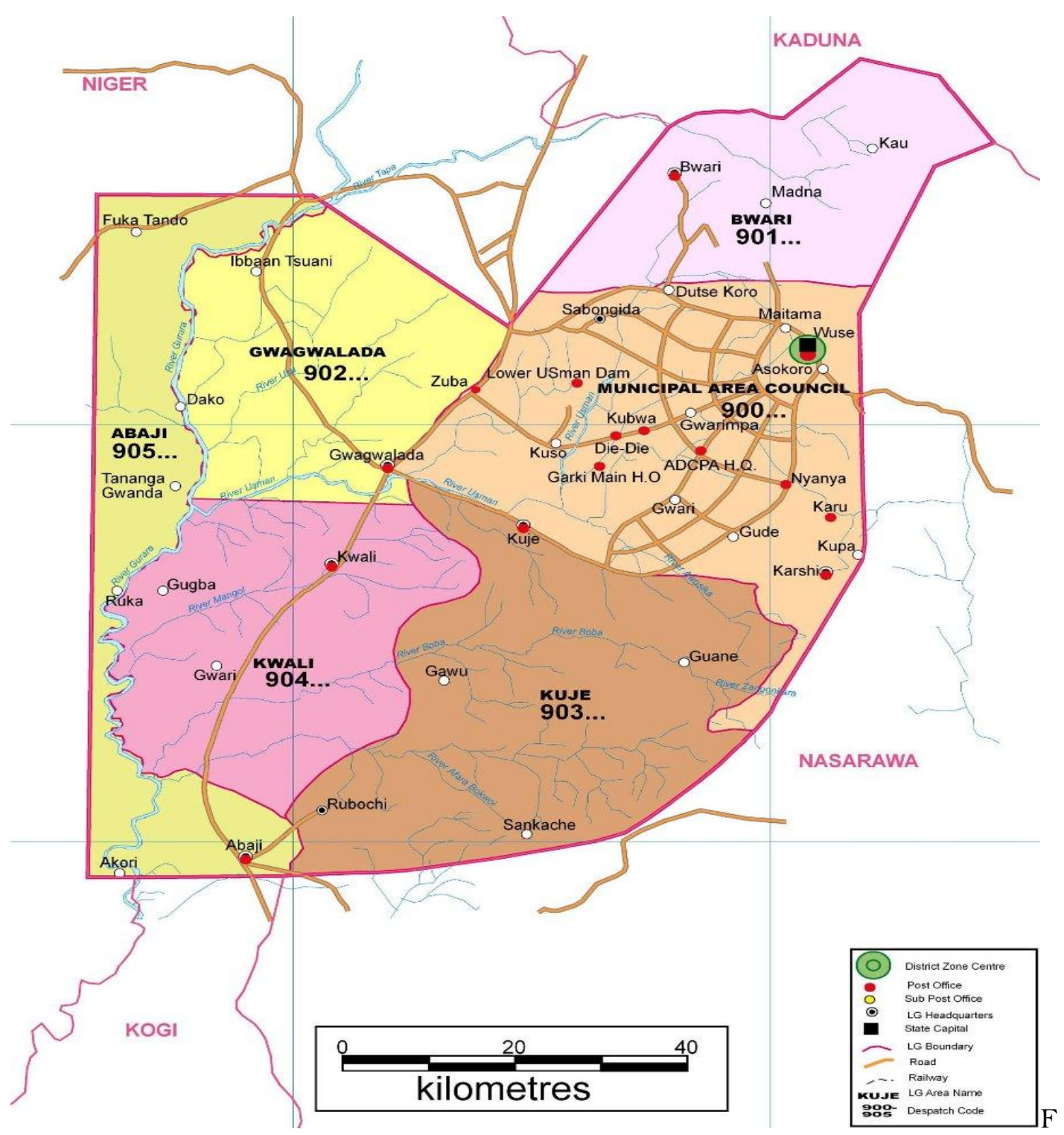

Figure-1.1. Map of Abuja showing Gwagwalada study Area and River usuma

Source: Abuja Geographical Information system (2013)

The Composite Map (Figure 1.2) shows the flood plains of River Usman which are areas likely to be flooded in an event of flood disaster. Farmers built houses and also farm along the fertile flood plains. All structures on flood plains are on potential harm's way and in danger of being washed away in the event of flood.

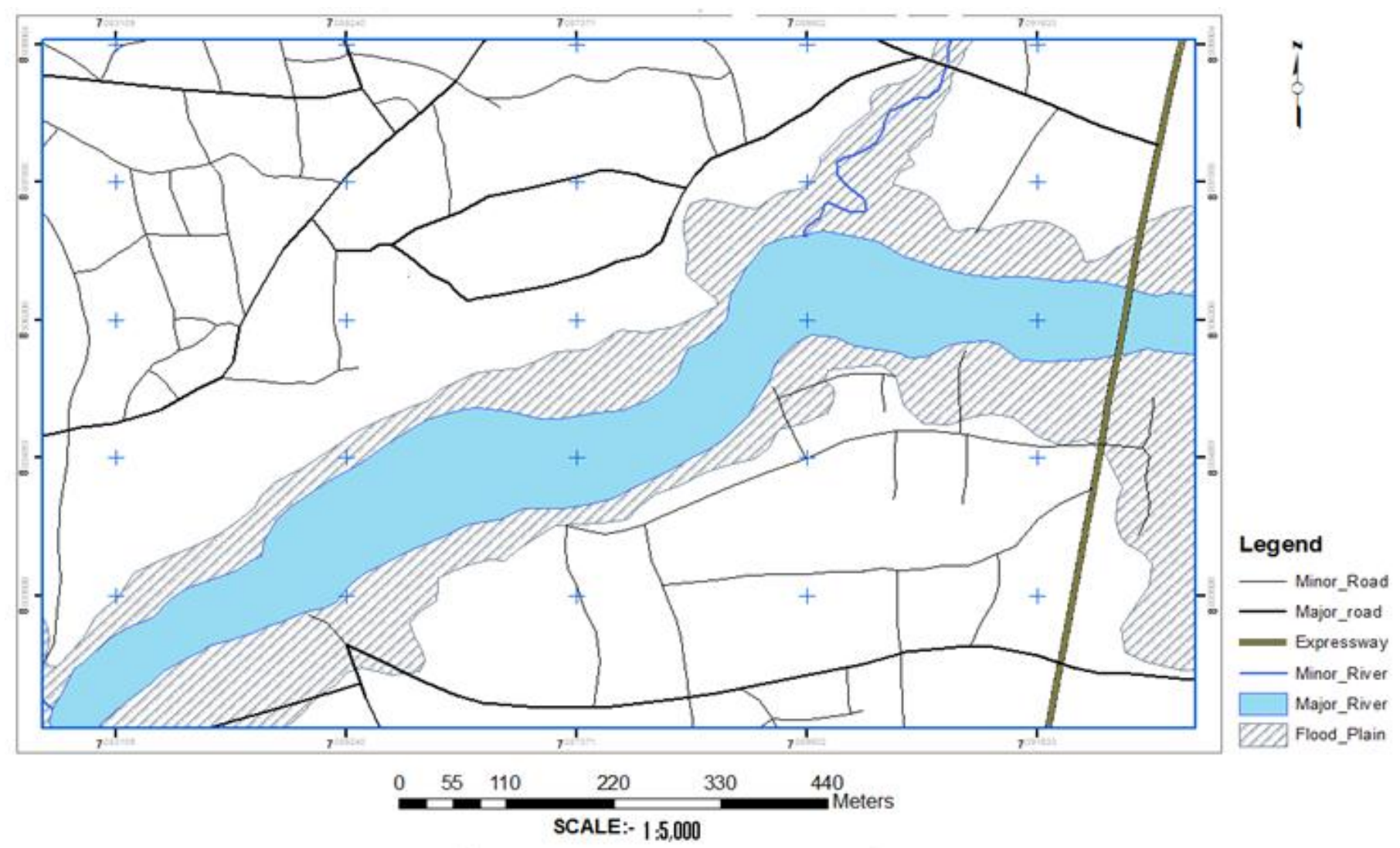

Source: Author Field Survey ( 2013)

Figure-1.2. Composite Map of Study Area 
The Map of Gwagwalada Area Council showing Dagiri Community (Figure 1.3) where the study was carried out. The map also shows river Usuman.

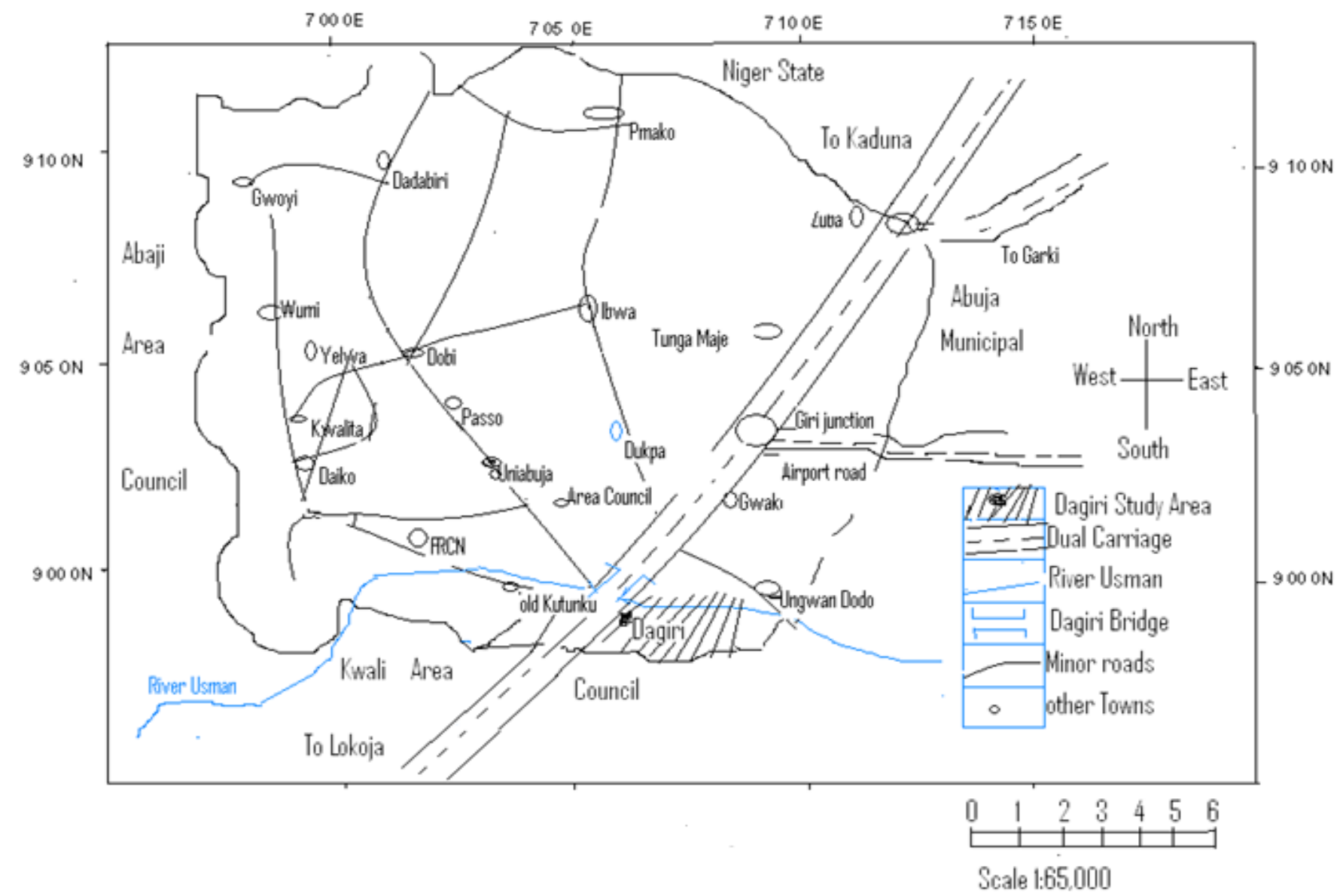

Source: Author feild Survey (2013)

Figure-1.3. Map of Gwagwalala Area Council,Showing Study Area

\section{Materials and Method}

This research made use of both qualitative and quantitative data. Data collection in this research work was fromPrimary sources.

The sampling frame for the study were rural farmers in Dagiri community and sampling technique used was random sampling of 112 household living along the River Usman, since they are those mostly affected by the flood incident

Data were analysed through the use of descriptive statistics, comprising of frequencies, simple percentages and tables supported with charts and graphs where necessary for further clarity to show the impact of flood. The researcher also ascertained the confidence interval of the respondents views at $95 \%$ confidence level.

A total of 112 questionnaires were administered and 112 questionnaires were correctly completed, retrieved and analysed for the study.

\section{Data Presentation Result and Discussion}

Flooding History of Dagiri Community.

Table-4.1. Flood Experience

\begin{tabular}{l|l|l}
\hline \multicolumn{3}{|c|}{ Table-4.1. Flood Experience } \\
\hline Response & Respondent & Percentage (\%) \\
\hline Yes & 112 & 100 \\
\hline No & 0 & 0 \\
\hline Total & 112 & 100 \\
\hline Source: Field survey, (2013) &
\end{tabular}

Result of the respondents view on flood experience reveals that all 112 respondents representing $100 \%$ had all experienced flooding event. From the respondents view it is very clear that flooding is a common occurrence in Dagiri Community of Gwagwalada Area Council. Table 4.1 above attest to the common knowledge of the flood by the indigenes.

Table-4.2. Sources of Flood Water

\begin{tabular}{l|l|l}
\hline Source & No of Respondent & Percentage (\%) \\
\hline River Gwagwalada & 110 & 98.21 \\
\hline Usman Dam & 108 & 96.43 \\
\hline Rainfall & 94 & 83.93 \\
\hline Source: Field Survey, $(0013)$ &
\end{tabular}

The source of flood water as indicated by our survey data in Table 4.2 are from three sources. 110 respondents representing $98.21 \%$ are of the opinion that river Gwagwalada is the source. 108 respondents representing $96.43 \%$ agreed that it is from Usman Dam and 94 respondents affirm that it is from rainfall. Above $80 \%$ of all the 
respondent are unanimous in their response that river Gwagwalada, Usman Dam and rainfall are the three source of flood water affecting Dagiri Community in Gwagwalada Abuja.

At $95 \%$ Confidence level and $\pm 5 \%$ error margin, River Gwagwalada was affirmed by $98.21 \%$ sample proportion of respondent's views as leading source of water for flooding in the community. This figure falls within the calculated confidence interval of between $96 \%$ and $100 \%$. From the calculated confidence interval it implies that if the entire Dagiri population were interviewed we have $95 \%$ confidence that between $96 \%$ and $100 \%$ of the population will choose River Gwagwalada as the leading source of flood water. This is an indication that flooding will be inevitable in the Community as long as the river remains. The best the government can do is to discourage people from building and farming close to the river or on flood plains and relocating those living there. The government can also provide proper channel and good network of drainages for easy flow of water.

Table-4.3. Element Often Affected by Flooding in your Community

\begin{tabular}{l|l|l}
\hline Element Affected by Flooding & Respondent & Percentage (\%) \\
\hline Crops & 78 & 69.64 \\
\hline Farm land & 80 & 71.43 \\
\hline Houses & 94 & 83.93 \\
\hline Properties & 88 & 78.57 \\
\hline Source: Field Survey, (2013)
\end{tabular}

The elements that are affected by floods in Dagiri Community were basically four, these were houses which are the worst hit by flooding according to $83.93 \%$ respondents of our survey data, this is because of the poor quality of materials used in building, closeness of house to the river, and the also building of house on flood plains. The next most affected element is properties according to $78.57 \%$ respondents; flood water washed away stored produce and some house hold items. Farm land and crops occupied the third and fourth places respectively in the order of elements affected by flood; these were the opinion of $71.43 \%$ and $69.64 \%$ respondents respectively in Table 4.3 .

Flood water destroys farm crops by washing them away and also eroding the top soil thereby destroying farmland. Flood also carry off household items like stored grains and other harvested crops which are destroyed in the process. In worst cases household livestock are swept of in raging flood.

At $95 \%$ Confidence level and $\pm 5 \%$ error margin, houses were affirmed by $83.93 \%$ sample proportion of respondent's views as most affected element during flooding in the community. This figure falls within the calculated confidence interval of between $77 \%$ and $89 \%$. From the calculated confidence interval it implies that if the entire Dagiri population were interviewed we have $95 \%$ confidence that between $77 \%$ and $89 \%$ of the population will choose houses as the most elements affected by flooding.

At $95 \%$ Confidence level and $\pm 5 \%$ error margin, Crop was affirmed by $69.64 \%$ sample proportion of respondent's views as least affected element during flooding in the community. This figure falls within the calculated confidence interval of between $61 \%$ and $77 \%$. From the calculated confidence interval it implies that if the entire Dagiri population were interviewed we have $95 \%$ confidence that between $61 \%$ and $77 \%$ of the population will choose Crop as the least element affected by flooding

Table-4.4. Effects of Flooding on the Family

\begin{tabular}{l|l|l}
\hline Effect of Flooding & Respondent & Percentage (\%) \\
\hline Loss of farm crop & 82 & 67.21 \\
\hline Loss of building structure & 86 & 76.79 \\
\hline Loss of agricultural land & 84 & 75.00 \\
\hline Loss of household properties & 85 & 75.89 \\
\hline Loss of lives & 8 & 7.14 \\
\hline Physical injuries & 20 & 17.86 \\
\hline Psychological injury & 30 & 26.79 \\
\hline Loss of animals & 60 & 53.57 \\
\hline Others & 0 & 0
\end{tabular}

The losses suffered by individual families from flood vary from family to family. From the results of our survey data in Table 4.4 heavy losses of above $70 \%$ incurred by most families in the Community were, loss of Agricultural land, loss of building and household properties. 8 respondents which represent $7.14 \%$ have suffered loss of lives as a result of flood disasters. From the analysis of our survey data it was also discovered that 20 respondents on the one hand and 30 on other hand suffered from physical and psychological injuries respectively. 60 and 82 respondents also experience loss of farm animals and cops respectively. The agricultural losses suffered by Dagiri community as a result of flood is great and leads to food insecurity this has necessitated the research to find ways to reduce the impact of flooding on the community to make the community more resilient to flood and to guarantee food security.

At $95 \%$ Confidence level and $\pm 5 \%$ error margin, the percentage sample proportion of respondent's views on loss of agricultural land by flooding is $75 \%$. This falls within the calculated confidence interval of between $67 \%$ and $83 \%$. From the calculated confidence interval it implies that if the entire Dagiri population were interview we have $95 \%$ confidence that between $67 \%$ and $83 \%$ of the population will choose loss of agricultural land as the third most affected element during flooding.

At $95 \%$ Confidence level and $\pm 5 \%$ error margin, the percentage sample proportion of respondent's views on loss of lives by flooding is $7.14 \%$. This falls within the calculated confidence interval of between $3 \%$ and $11 \%$. From the calculated confidence interval it implies that if the entire Dagiri population were interview we have $95 \%$ confidence that between $3 \%$ and $11 \%$ of the population will choose loss of lives as the least affected element during flooding.

Figure 1: Estimates of Damages Done by Flood for three Years 
The result of our survey data on the estimate of total damages suffered by household was done for three consecutive years (Figure 1 below). Beginning from 2010, it would be observed that 64 respondents suffered losses less than $\$ 100$, 000 while 28 respondent suffered loss above $\$ 100$, 000, altogether 92 respondents suffered losses. In 2011 , they was slight reduction in the number of people that suffered losses compared to the preceding year. In 2011 a total of 84 respondents suffered losses. 60 suffered losses less than $\$ 100$, 000 while 24 suffered losses above $\$ 100$, OOO. In 2012 the figure was high 91 respondents suffered losses compared to the previous years. 68 suffered losses less than $\$ 100$, 000 while 31 suffered losses above $\$ 100$, 000 this could be attributed to the widespread flood incident in the country the worst since the history of the nation. Find below graphical representation of estimates of damages suffered by the rural farmers for three years of 2010, 2011 and 2012. The losses suffered by farmers leads to food shortage and consequently food insecurity. $(1 \$=165.00)$

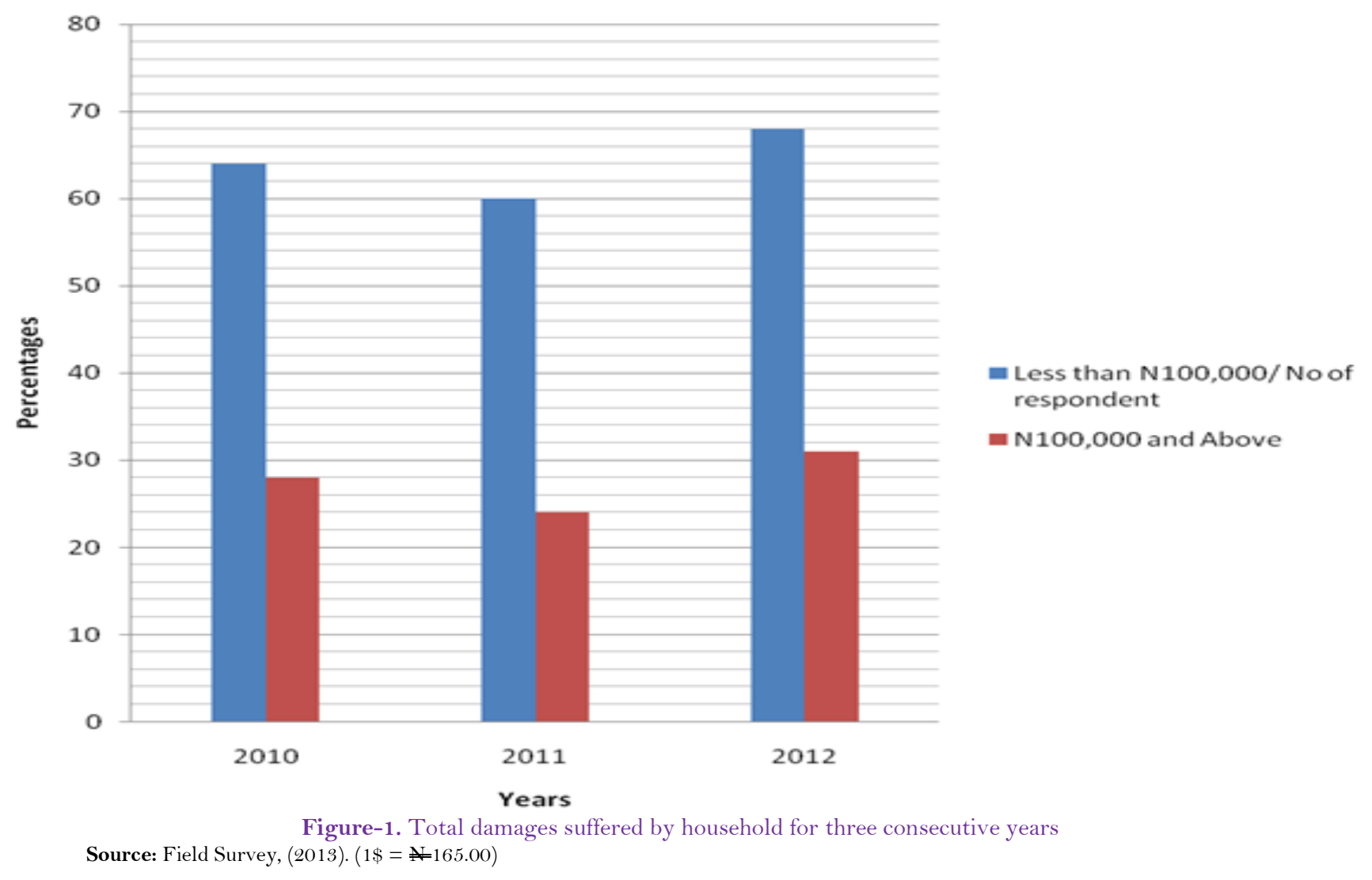

\section{Conclusion}

The impact of flood in the community is obvious and the people are overwhelmed by the challenges caused by the flood, at present there is no community flood risk management initiative on ground, there is also very poor government presence in the control and management of flood in the community making the impact of flood on agricultural productivity heavy on the community. The flood has hampered sustainable development and also frustrated the millennial development goals of the government especially in the areas of food security.

An important flood risk factor identified is the indiscriminate building of houses on flood paths and close to the river making the impact of flood heavy. The farmers should be prevented from farming and living on flood plains and areas prone to flooding. The government authorities can come up with zoning laws and together with the community to constitute a committee to prevent people from building and farming on flood plains. This zoning legislation should be strictly enforced.

One of the major causes of flood from my research findings is the release of water from Dams. Dagiri Community must be carried along by the local authorities and be engaged in dissemination of flood warning for the effectiveness of flood mitigation. There should be a partnership between government and the community, the government should take initiative and come to the aid of the people by putting in place well informed community warning/dissemination systems. This system is critical to the success of managing flood risk by communities besieged with the problem of flood disaster. Before the release of water from Dam early warning should be carried out in the Community.

The result of my research revealed flash flooding as the most prevalent type of flood in Dagiri Community. The construction of good network of giant drainages to channel water to the river will address the issue of flash flood in the Community.

Government disaster management authorities should see it as a duty to visit and consult communities to identify community resources that can be used for flood alleviation schemes as a way of community participatory approach. This should be done from the earlier stage, and also train members of the communities on flood risk management practices using informal approaches to individuals household at risk through 'community dialect' wherever possible. This will increase community coping capacity

\section{References}

[1] World Bank, "Poverty and hunger: Issues and options for food security in developing countries," presented at the Paper Presented World Bank, Washington DC, 1986.

[2] Food and Agriculture Organization FAO, "Rome declaration on world food security. World food summit, November. Rome, Italy." Available http://www.fao.org/docrep/003/w3613e/w3613e00.HTM [Accessed 04 March 2014$], 1996$.

[3] K. M. K. John, M. S. Demi, and P. K. A. Ditchfield, "Comparative analysis of food security status of farming households in the costal and the forest communities of central region of Ghana," Asian Journal of Empirical Research, vol. 3, pp. 39 - 61, 2013. 
NEMA, "Flood disaster monitor in Nigeria. A Brief Report." Available www.nema.org.ng, 2010.

NEMA, "Flood disaster monitor in Nigeria. A Brief Report." Available www.nema.org.ng, 2011.

C. Jeronim, K. Panagiotis, K. Marco, and S. Mark, "A model of vulnerability to food insecurity. ESA Working Paper No. 10-03. Agricultural Development Economics Division." Available http://www.fao.org/docrep/012/al318e/al318e.pdf [Accessed 01 March 20147, 2010.

A. Khatri-Chatri and K. L. Maharjan, "Food security and coping strategies in rural areas of Nepal: A case study of Dailekh district in mid-Western development region," Journal of International Development and Cooperation, vol. 12, pp. 25 - 45, 2006.

Population Reference Bureau, "World population data sheet." Available www. prb.org/publications/Datasheets/2010/2010wpds [Accessed 15 March 2014], 2010.

[9] Food and Agriculture Organization FAO, Guidelines for measuring household and individual dietary diversity. Rome: Food and Agriculture Organization, 2010.

[10] G. K. Von, D. Headey, C. Béné, L. Haddad, T. Olofinbiyi, D. H. Wiesmann, H. Fritschel, S. Yin, Y. C. Yohannes, C. Foley, V. O. C., and B. Iseli, 2013 global hunger index: The challenge of hunger: Building resilience to achieve food and nutrition security. Bonn, Washington, DC, and Dublin: Welthungerhilfe, International Food Policy Research Institute, and Concern Worldwide, 2013.

[11] Food and Agriculture Organization FAO, The integrated phase and humanitarian phase classification technical manual. Nairobi: Food Security Analysis Unit for Somalia, 2006.

[12] O. A. Abimbola and A. A. Kayode, "Food insecurity status of rural households during the post-planting season in Nigeria," Journal of Agriculture and Sustainability, vol. 4, pp. 16-35, 2013.

[13] NEMA, "Flood disaster monitor in Nigeria. A Brief Report." Available www.nema.org.ng, 2012.

[14] B. Wisner, P. Blaikie, T. Cannon, and I. Davis, At risk - natural hazards, people's vulnerability and disasters. Wiltshire: Routledge, 2004 .

[15] Luis Flores Ballesteros, "What determines a disaster? 54 Pesos Sep 2008: 54 Pesos 11 Sep 2008." Available http://54pesos.org/2008/09/11/what-determines-a-disaster/, 2008.

[16] D. Alexander, Principles of emergency planning and management. Harpended: Terra Publishing, 2002.

[17] R. Lavalla, S. Stoffel, J. Kortez, B. Rudolph, and L. Murphy, Disaster planning manual: How to write a community disaster coordination plan. Olympia, WA: The Emergency Response Institute Inc, 1989.

[18] A. T. Jayasselen, "Drought and flood assessment and monitoring using remote sensing and GIS application in agricultural meteorology," Journal of Flood and Drought Monitoring, vol. 3, pp. 291-313, 2006.

[19] K. Smith, "Environmental hazards: Assessing risk disaster. London Routeledge," Journal of Disaster Risk Management, vol. 2, pp. 30 $-43,1991$.

[20] M. O. Ojo, Some implications of government economies policies for the financing and development of agriculture in Nigeria in readings in agricultural finance, A. Okorie and M. O Ijere Eds. Lagos: Longman, 1998.

[21] F. C. Obasi and S. E. Agu, "Economies of small scale rice farmers under different production systems in South Eastern Nigeria," Journal of Agriculture, Business and Rural Development, vol. 1, p. 2, 2002.

Citation | Ikani Daniel Idoko (2016). An Impact Assessment of Flooding on Food Security among Rural Farmers in Dagiri Community, of Gwagwalada Area Council, Abuja. Nigeria. Agricultural Development, 1: 6-13.

History:

Received: 26 November 2015

Revised: 28 December 2015

Accepted: 4. January 9016

Accepted: 4 January 2016

Published: 12 January 2016
Licensed: This work is

Attribution 3.0 License (oc)

Publisher: Eastern Centre of Science and Education of the content. Any queries should be directed to the corresponding author of the article.
Funding: This study received no specific financial support.

Competing Interests: The author declares that there are no conflicts of interests regarding the publication of this paper.

Transparency: The author confirms that the manuscript is an honest, accurate, and transparent account of the study was reported; that no vital features of the study have been omitted; and that any discrepancies from the study as planned have been explained

Ethical: This study follows all ethical practices during writing. 